\title{
Correction to: Developing a feasible and sensitive judgement bias task in dairy cows
}

\author{
Louise Kremer ${ }^{1,2}\left(\right.$ Cornelis G. van Reenen $^{1,2} \cdot$ Bas Engel $^{3} \cdot$ Eddie A. M. Bokkers $^{1}\left(\mathbb{D} \cdot\right.$ Sabine K. Schnabel $^{3}$ (1) . \\ Jozef T. N. van der Werf ${ }^{2}$. Laura E. Webb ${ }^{1}$ (1)
}

Published online: 27 November 2021

(c) Springer-Verlag GmbH Germany, part of Springer Nature 2021

\section{Correction to: Animal Cognition \\ https://doi.org/10.1007/s10071-021-01563-8}

In the Original publication of the article, the second author name was incorrectly published as Cornelius G. van Reenen, the correct name should read as Cornelis G. van Reenen. This has been corrected in this paper. In addition, at the end of the abstract, it is written "We conclude that using an air puff as punisher led to the most sensitive, yet non-repeatable-BT for dairy cows". The correct should read as; "We conclude that using an air puff as punisher led to the most sensitive, yet non-repeatable, JBT for dairy cows". This has been corrected here.
Publisher's Note Springer Nature remains neutral with regard to jurisdictional claims in published maps and institutional affiliations.

The original article can be found online at https://doi.org/10.1007/ s10071-021-01563-8.

Louise Kremer

louise.kremer@wur.nl

1 Animal Production Systems Group, Wageningen University and Research, Wageningen, The Netherlands

2 Wageningen Livestock Research, Wageningen University and Research, Wageningen, The Netherlands

3 Biometris, Wageningen University, Wageningen University and Research, Wageningen, The Netherlands 